This item was submitted to Loughborough's Research Repository by the author.

Items in Figshare are protected by copyright, with all rights reserved, unless otherwise indicated.

\title{
Inkjet printed dipole antennas on textiles for wearable communications
}

\section{PLEASE CITE THE PUBLISHED VERSION}

http://digital-library.theiet.org/content/journals/iet-map

\section{PUBLISHER}

(c) The Institution of Engineering and Technology

\section{VERSION}

AM (Accepted Manuscript)

\section{LICENCE}

CC BY-NC-ND 4.0

\section{REPOSITORY RECORD}

Chauraya, Alford, W.G. Whittow, J.C. Vardaxoglou, Yi Li, Russel Torah, Kai Yang, Steve Beeby, and John Tudor. 2019. "Inkjet Printed Dipole Antennas on Textiles for Wearable Communications". figshare. https://hdl.handle.net/2134/12841. 
This item was submitted to Loughborough's Institutional Repository (https://dspace.lboro.ac.uk/) by the author and is made available under the following Creative Commons Licence conditions.

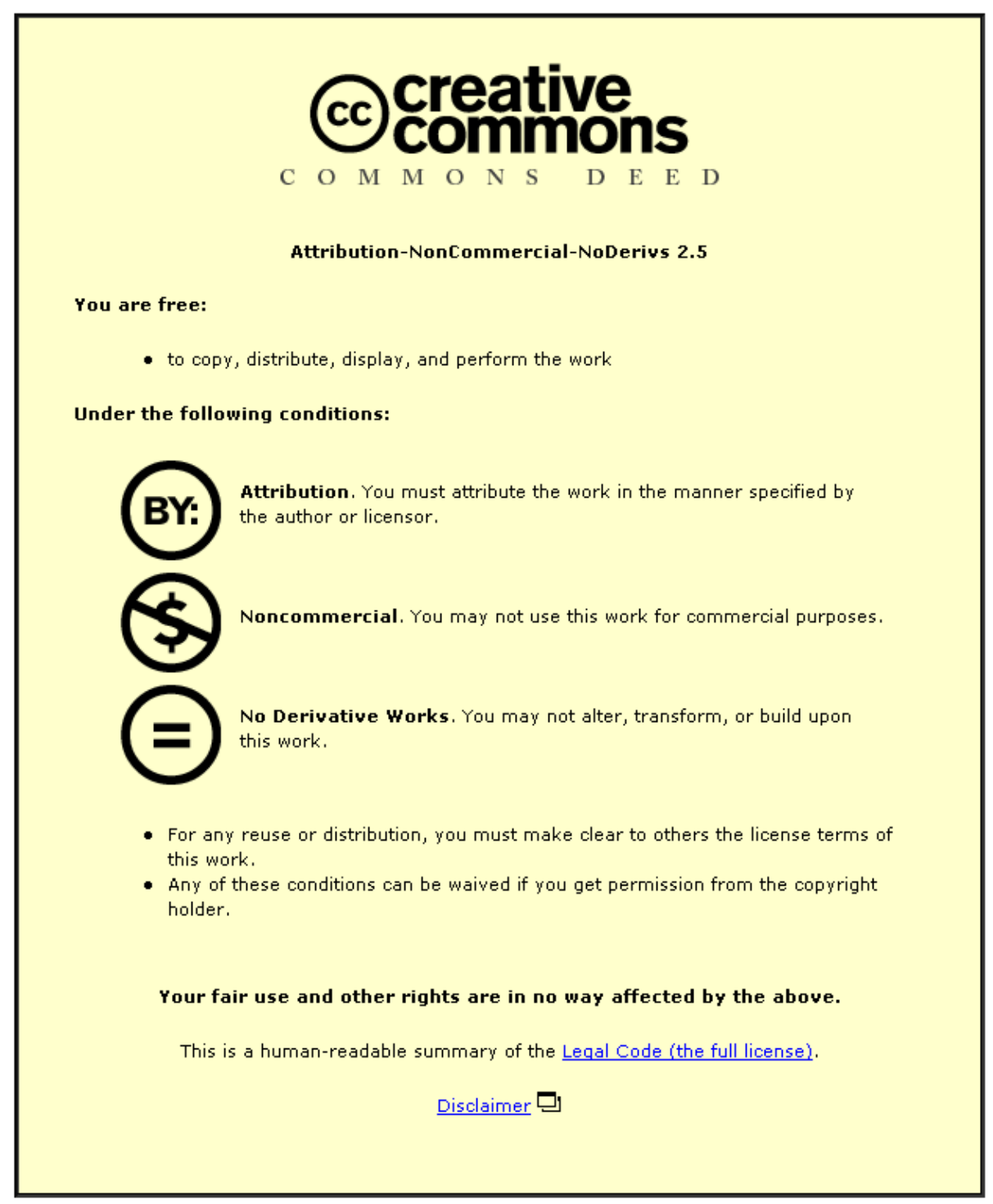

For the full text of this licence, please go to: http://creativecommons.org/licenses/by-nc-nd/2.5/ 


\title{
Inkjet Printed Dipole Antennas on Textiles for Wearable Communications
}

\author{
Alford Chauraya ${ }^{1}$, William G. Whittow ${ }^{2}$, J(Yiannis) C. Vardaxoglou ${ }^{3}$, \\ $\mathrm{Yi} \mathrm{Li}^{4}$, Russel Torah ${ }^{5}$, Kai Yang ${ }^{6}$, Steve Beeby ${ }^{7}$, and John Tudor ${ }^{8}$ \\ 1, 2, 3 School of Electronic, Electrical and Systems Engineering \\ Loughborough University, Loughborough, UK \\ a.chauraya@lboro.ac.uk; w.g.whittow@lboro.ac.uk; j.c.vardaxoglou@lboro.ac.uk \\ 4, 5, 6, 7, 8 School of Electronics and Computer Science, University of Southampton, \\ Southampton, UK \\ yl1g08@ecs.soton.ac.uk; rnt@ecs.soton.ac.uk; ky2@ecs.soton.ac.uk; \\ spb@ecs.soton.ac.uk; mjt@ecs.soton.ac.uk
}

\begin{abstract}
This paper presents an inkjet printed textile antenna realised using a novel fabrication methodology. Conventionally, it is very difficult to inkjet print onto textiles due to surface roughness. This paper demonstrates how this can be overcome by developing an interface coated layer which bonds to a standard polyester cotton fabric, creating a smooth surface. A planar dipole antenna has been fabricated, simulated and measured. This paper includes DC resistance, RF reflection coefficient results and antenna radiation patterns. Efficiencies of greater than $60 \%$ have been achieved with only one layer of conducting ink. The paper demonstrates that the interface layer saves considerable time and cost in terms of the number of inkjet layers needed whilst also improving the printing resolution.
\end{abstract}

\section{Introduction}

The worldwide wearable technology market is expected to exceed $£ 3.75$ billion by 2016 (www.computerworld.com). This is simultaneously driven by advancing technology and emerging applications. Smart fabrics are traditional fabrics with integrated active functionality, that can sense and react to environmental stimuli, such as mechanical, 
Final author version. Paper published in IET Microwaves, Antennas \& Propagation, Volume 7, Issue 9, 18 June 2013, p. 760 - 767, DOI: 10.1049/iet-map.2013.0076, Print ISSN 1751-8725, Online ISSN 1751-8733

thermal, chemical or magnetic [1]. In parallel with this, wireless connectivity is already essential to everyday life and is expected to become even more ubiquitous. Therefore incorporating flexible fabric antennas could have many potential applications. Flexible materials improve comfort and the integration of antennas into clothing means that they do not need to be hand-held [2]. This technology has various wearable applications including medical, sports training, military and emergency services [3]. For example, soldiers can communicate together by means of fabric antennas integrated in their uniforms or carry jamming devices to counter improvised explosive devices. Wearable Electrocardiography (ECG) systems can send the signal wirelessly from the patient, thus improving patient comfort [4]. Furthermore, telemedicine will become a vital tool in dealing with the aging population - where ten million people alive in the UK today are expected to live to 100 . Radio-Frequency Identification (RFID) tagging on clothes is another important area as it enables efficient product and person tracking.

Many papers have been published about wearable antennas, including these three papers that have reviewed the area [5-7]. Body-centric communications between multiple wearable antennas on the same person has been investigated in detail [8], [9]. When antennas are placed in close proximity to the human body, the specific absorption rate (SAR) must comply with International Commission on Non-lonizing Radiation Protection (ICNIRP) limits [10]. The flexibility of the textiles means that an additional margin of performance must be included in the design to allow for crumpling [11], stretching and bending [12]. Integration into clothing means that the washability of the antennas has been considered [13]. The antennas must also function in harsh environments [14] and in humid conditions [15].

Various manufacturing techniques considered for wearable antennas include conducting paint, conducting metal coated nylon, screen printing and liquid crystal polymer [16]. 
Final author version. Paper published in IET Microwaves, Antennas \& Propagation, Volume 7, Issue 9, 18 June 2013, p. 760 - 767, DOI: 10.1049/iet-map.2013.0076, Print ISSN 1751-8725, Online ISSN 1751-8733

Wearable antennas can also be fabricated by depositing a conductive layer on top of the fabric by either metal plating [17], [18] or by sticking-on metalized adhesive tape [19].

The first knitted copper-yarn based fabric antenna was reported by Salonen et al in 2003 [20]. The entire antenna was constructed in fabric with a fleece substrate and the radiation element and ground plane were made of knitted copper. A woven textile antenna was announced by Tanaka et al in 2003 [21]. The material of the antenna patch and the ground plane were made of woven conductive fabric and then sewn into clothing. Embroidered antennas made with conducting threads have recently been considered [22].

Printing is another method to deposit a conductive layer on flexible substrates. Screen printing is the most widely used printing technique to realize textile antennas as it can easily pattern conductive paste onto fabric to form a flexible strong and suitably thick functional layer [13], [23]. Antennas have been screen printed on paper [24] and PET [25]. Transmission lines for RF and microwave systems have been screen printed on cotton [26]. The technique of inkjet printing antenna structures can be an advantageous manufacturing technique as: the antenna can be created within minutes of finalising the design; the finish is aesthetic; it requires minimal material consumption and as no mask is required there is the flexibility to change the design regularly. Inkjet printing uses silver or copper nanoparticles in solution to create conducting lines. The process is an additive process which does not require environmentally harmful etching chemicals. Carbon nanotube inks are also used but typically have lower conductivities than metallic inks. The conducting layers are very thin, on the order of one micron, and hence it is very difficult to print on rough, uneven or porous surfaces such as fabrics [27]. Inkjet printed antennas have been printed on paper [28-32]; PET [33], [34]; Kapton [35-37] and a flexible ceramic composite [38]. Inkjet printing has the following inherent technical challenges when fabrics are the substrate: i) it is difficult achieving a highly conductive continuous track on the rough fabric with a thin inkjet printed layer; ii) the majority of fabrics cannot withstand curing temperatures above $150^{\circ} \mathrm{C}$; iii) 
Final author version. Paper published in IET Microwaves, Antennas \& Propagation, Volume 7, Issue 9, 18 June 2013, p. 760 - 767, DOI: 10.1049/iet-map.2013.0076, Print ISSN 1751-8725, Online ISSN 1751-8733

resilience to stretching and bending and iv) achieving high antenna efficiency. The majority of papers in the literature do not include efficiency values for inkjet printed antennas as these are typically low. The performance can be improved by printing multiple layers (but this adds to increased manufacturing times and costs). Sintering the ink or laser melting the silver particles together has also been used to improve the conductivity of lines containing conducting metallic flakes [39]. The authors have recently presented some preliminary results of an inkjet printed antenna on a textile substrate [40]. Previous research has indicated that small gaps and cracks in conducting sections can capacitively couple [41].

This paper is structured as follows: Section 2 will provide more details of the inkjet printing process and the novel interface layer. Sections 3 and 4 will summarise the DC resistance and RF results respectively. Finally conclusions will be drawn in Section 5 .

\section{Printing on Textiles}

Direct write printing is defined as an additive manufacturing method in which the deposited patterns directly follow a pre-designed computer layout without utilising masks or subsequent etching processes [42] as shown in Figure 1. Direct write can deposit and pattern different thin film materials necessary for the fabrication of components and systems such as those found in electronic devices, sensors and microelectromechanical systems (MEMS) [43]. Inkjet printing is a widely used direct write deposition tool which has been rapidly migrated to electronics fabrication in recent years. It is a key printing technique which has not been widely applied to wearable textile antenna fabrication. 
Traditional fabrication

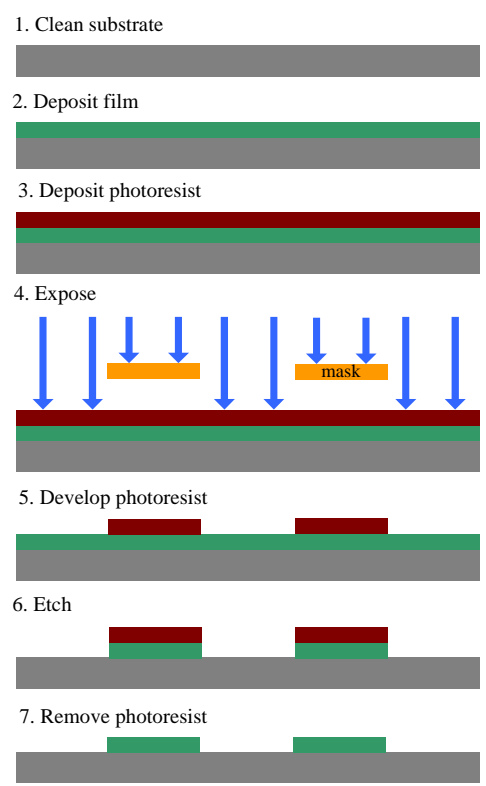

Screen printing

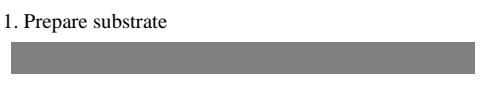

2. Print active paste

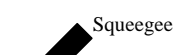

Active paste
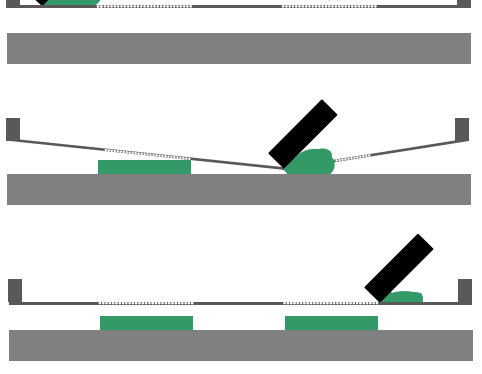

3. Curing process
Direct write printing

1. Prepare substrate

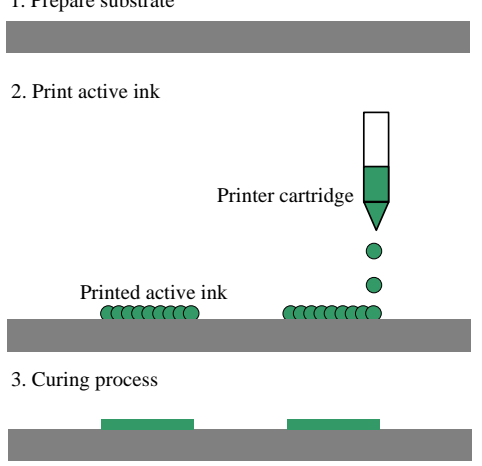

Figure 1. A comparison of the processing steps involved in subtractive microfabrication, screen printing and additive direct write printing.

It is possible to print directly on to the fabric but due to the high solvent content $(\sim 85 \%)$ of the inks required to ensure inkjet printability, the pattern would dissipate into the textile and cannot produce a continuous conducting track without many layers being printed.

\section{$2.1 \quad$ Inkjet printing}

A Dimatix DMP-2831 inkjet printer was used in this research. This printer uses a disposable piezoelectric head print cartridge with an ink capacity of $1.5 \mathrm{ml}$. It has sixteen nozzles each capable of producing a droplet volume of $10 \mathrm{pL}$. The printed pattern resolution is controlled by adjusting the angle of the print head in the printer to provide a drop spacing of between 5 and $254 \mu \mathrm{m}$ (5080 to $100 \mathrm{dpi}$ ). When printing inks with electronic functionality, the resolution is critical to the performance of the printed ink. If the droplet spacing is too small, the volume of printed ink per unit area will be too high which often results in pattern bleeding. If the droplet spacing is too large, then the pattern definition will be poor and the electrical characteristics, such as conductivity, will be reduced or lost entirely. Suitable printable inks 
Final author version. Paper published in IET Microwaves, Antennas \& Propagation, Volume 7, Issue 9, 18 June 2013, p. 760 - 767, DOI: 10.1049/iet-map.2013.0076, Print ISSN 1751-8725, Online ISSN 1751-8733

have a narrow acceptable range of rheological properties which ensure that the droplets fire continuously in the required landing location. An ideal ink for printing with the DMP-2831 should have a stable suspension with low evaporation, a viscosity of 10 to $12 \mathrm{mPa} . \mathrm{s}$ and a surface tension of 28 to $33 \mathrm{mN} / \mathrm{m}$. Increasing the temperature improves the fluidity of the ink but can also increase the ink's evaporation rate leading to additional clogging. The drive waveform and voltage were adjusted to produce a spherical droplet with no tail, known as a ligand, with a drop velocity of $\sim 7-9 \mathrm{~m} / \mathrm{s}$. After printing, the inks must be cured to remove the solvents.

\section{$2.2 \quad$ Ink selection}

SunChemical's thermally-cured inkjet printable conductive silver ink (U5714) was selected for printing the conductor because the surface tension and viscosity are suitable for the DMP-2831 printer. In addition, the silver ink can be cured at $150^{\circ} \mathrm{C}$ for 10 minutes making it more compatible with fabric applications than other commercial inks which typically require higher temperatures $\left(>200^{\circ} \mathrm{C}\right)$ which will damage the fabric. The $10 \mathrm{pL}$ print heads for the DMP-2831 have a nozzle diameter of $\sim 21.5 \mu \mathrm{m}$ which produce a droplet of $60 \mu \mathrm{m}$ diameter.

The drop spacing was set to $15 \mu \mathrm{m}$ for printing the conductive pattern to provide good conductivity and line edge definition combined with acceptable ink usage. The ink showed good jetting properties with a droplet velocity of $8 \mathrm{~m} / \mathrm{s}$ so additional print head heating was not required.

\subsection{Substrate selection}

Four substrates were selected as a comparison: i) Kapton; ii) a stretchable fabric; iii) polyester/cotton fabric and iv) polyester/cotton fabric with a printed interface layer. 
Final author version. Paper published in IET Microwaves, Antennas \& Propagation, Volume 7, Issue 9, 18 June 2013, p. 760 - 767, DOI: 10.1049/iet-map.2013.0076, Print ISSN 1751-8725, Online ISSN 1751-8733

$100 \mu \mathrm{m}$ thick Kapton which was selected for the initial flat, smooth substrate material exhibited few uneven dents and bulges $(<5 \mu \mathrm{m})$. Kapton is a polyimide film developed by DuPont which has very good flexibility over a wide temperature range (normally from $-273^{\circ} \mathrm{C}$ to $\left.+400^{\circ} \mathrm{C}\right)$ and is resistant to many chemical solvents (http://www2.dupont.com/Kapton/en_US/). Because of its chemical and physical properties, it is widely used in flexible electronics as a substrate or an insulating layer.

A commercial polyurethane coated stretchable fabric supplied from Plastibert Ltd. (www.plastibert.be) was also selected; this is a lycra fabric that is typically used in medical applications. This coated fabric substrate was chosen as the second stage substrate because it provides an intermediate step between the smooth Kapton film and the rough fabric. However, the laminated polyurethane layer on top of the stretchable fabric is not as smooth as the Kapton film. Its roughness is around $10-20 \mu \mathrm{m}$ continuously across the whole laminated layer. The manufacturer datasheet states that the maximum temperature it can sustain continuously is $80^{\circ} \mathrm{C}$. Therefore, before printing, the fabric was subjected to one curing cycle of $150^{\circ} \mathrm{C}$ for 10 minutes, representing the curing condition of the silver ink, which showed no observable damage to the fabric. A scanning electron microscope (SEM) image of the Plastibert polyurethane coated stretchable fabric is shown in Figure 2 which shows the higher surface roughness $(10-20 \mu \mathrm{m})$ continuously across the whole coated area. 


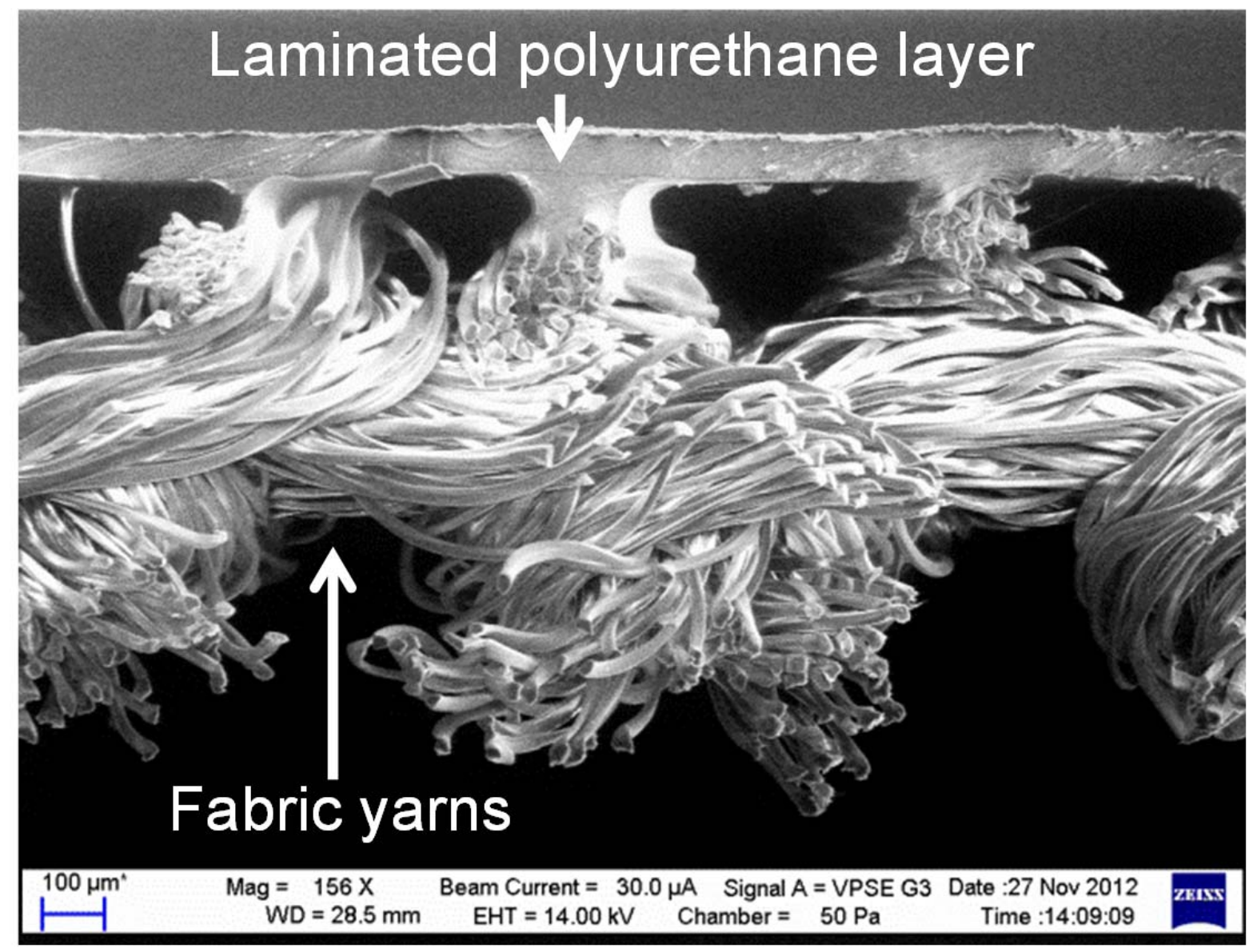

Figure 2. Cross sectional view SEM images of Plastibert polyurethane coated stretchable fabric

The $65 / 35$ polyester cotton fabric is the most commonly used fabric for standard clothing. However, it has a number of physical properties that make inkjet printing based deposition difficult. The temperature which it can withstand is a challenge meaning a sufficiently low curing temperature for inks is required. The standard $65 / 35$ polyester cotton fabric was supplied by Klopman International (www.klopman.com) and their characterization data shows that the fabric can be thermally cured at $150^{\circ} \mathrm{C}$ for 45 minutes, $175^{\circ} \mathrm{C}$ for 15 minutes, $200^{\circ} \mathrm{C}$ for 10 minutes or $225^{\circ} \mathrm{C}$ for 3 minutes without noticeable fabric colour changing or degradation. Therefore, a $150^{\circ} \mathrm{C}$ curing temperature provides a suitable compromise between sufficient conductivity and compatibility with fabrics. Furthermore, its surface roughness is much higher than the other two substrates selected. Manufacture datasheet reports its arithmetic mean deviation of the surface roughness is $143.3 \mu \mathrm{m}$. 
Final author version. Paper published in IET Microwaves, Antennas \& Propagation, Volume 7, Issue 9, 18 June 2013, p. 760 - 767, DOI: 10.1049/iet-map.2013.0076, Print ISSN 1751-8725, Online ISSN 1751-8733

\section{$2.4 \quad$ Interface layer}

To reduce the standard $65 / 35$ polyester cotton fabric surface roughness, the fabric is pretreated using a screen printed interface layer (Fabink-UV-IF1 from Smart Fabric Inks Ltd.) before further inkjet printing. Fabink-UV-IF1 is a UV curable polyurethane acrylate based interface paste. It can be applied on various textiles, including cotton, polyester/cotton, Lycra ${ }^{\circledR}$ etc as well as materials such as alumina and Kapton. It has been designed as a screen printable paste and cured films show good adhesion to textiles, good flexibility and surface smoothness. The screen printed interface layer is only applied in the area surrounding the future inkjet printed design so that, unlike the commercial coated fabric, the properties of the fabric such as breathability and flexibility are maintained. This is a significant advantage when compared to the commercial coated fabric shown in Figure 2 or fabrics with an attached Kapton film, both of which lack breathability since the film covers the entire fabric. The screen printed interface layer has an average thickness of $200 \mu \mathrm{m}$. The interface coated standard (ICS) fabric had a surface roughness of less than $5 \mu$ m An SEM image of the interface layer is shown in Figure 3. 


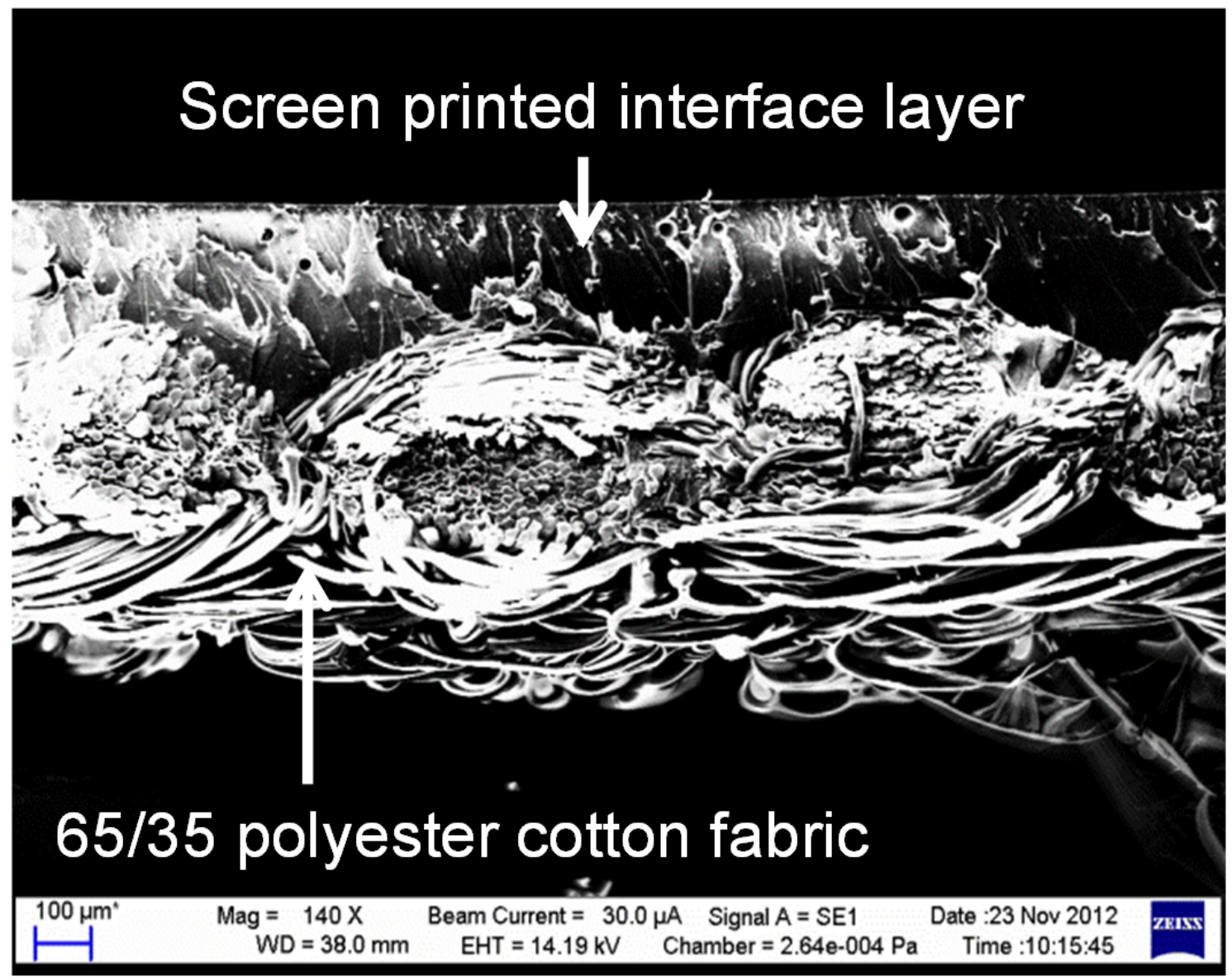

Figure 3. Cross sectional view SEM images of standard $65 / 35$ polyester cotton fabric with interface layer

\subsection{Inkjet printing on substrates}

This section outlines the process to inkjet print the conducting fabrics. The first step is to wipe the substrate surface with lint free cleanroom wipes dipped in deionised water. This step removes any contamination on the substrate surface and ensures a homogenous surface energy across the printing area. This ensures the contact angle for each printed droplet is the same which results in a sharper patterned layer. The next step is to inkjet print the conductive silver ink. After printing, the conductive pattern is cured for 10 minutes at $150^{\circ} \mathrm{C}$. 
Due to the surface roughness of the stretchable fabric $(10-20 \mu \mathrm{m})$, the inkjet printer is set to print two layers with $15 \mu \mathrm{m}$ resolution on Plastibert. When two silver layers are printed, they are deposited one layer after another, with the subsequent curing process carried out after both layers were inkjet printed. One and two conductive silver layers were chosen to inkjet print on to interface-treated polyester cotton fabric. In general, an additional printed layer is required for the textile substrates compared to Kapton to ensure sufficient conductivity and good pattern definition as a result of the increased surface roughness and relatively poor chemical resistance. Two inkjet printed layer are printed resulting in a thickness of 3 microns as shown in Figure 4 (b).
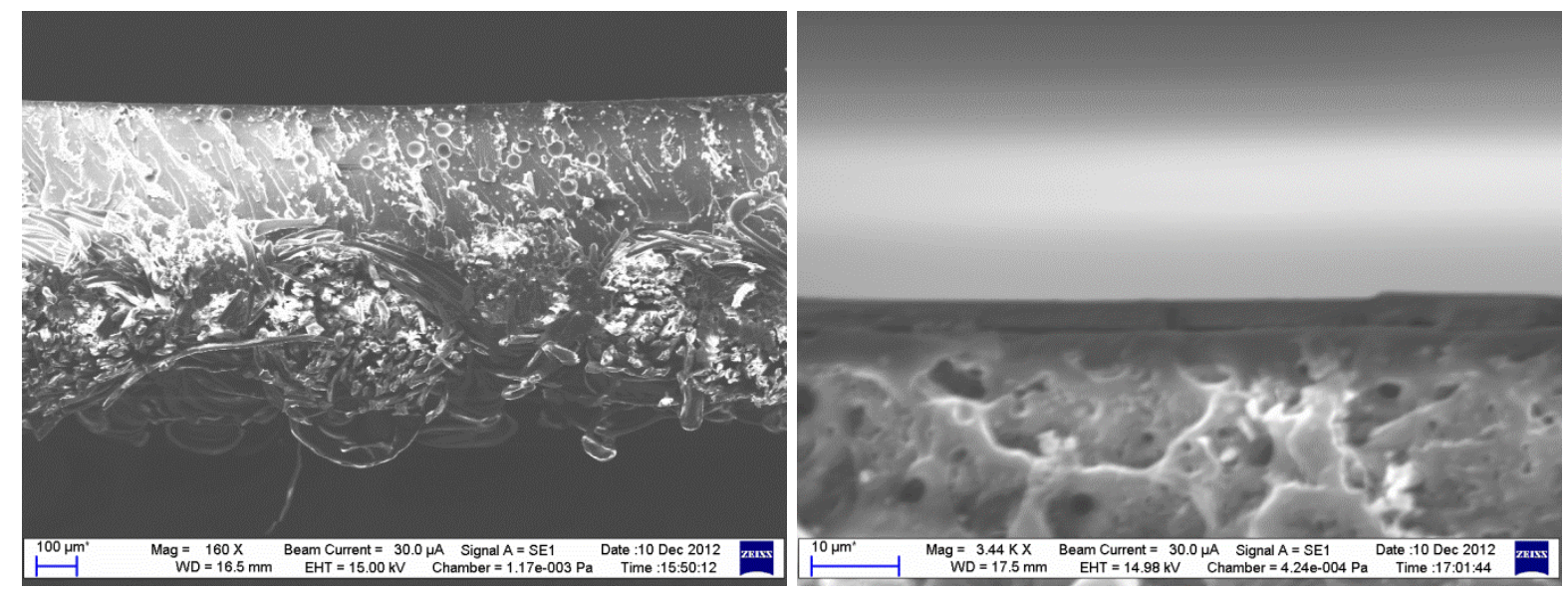

Figure 4. SEM images of printed layers: (a) The interface layer and (b) the inkjet printed layer

\section{DC Resistance Measurements}

The printed dipole arms were $31.3 \mathrm{~mm}$ long and $2 \mathrm{~mm}$ wide. The configuration of the inkjet printed dipole prototype structure, along with its dimensions, is shown in Figure 5 (a). A digital microscope image of the dipole on Kapton and the Interface Coated Substrate (ICS) are shown in Figure $5(b-c)$. 


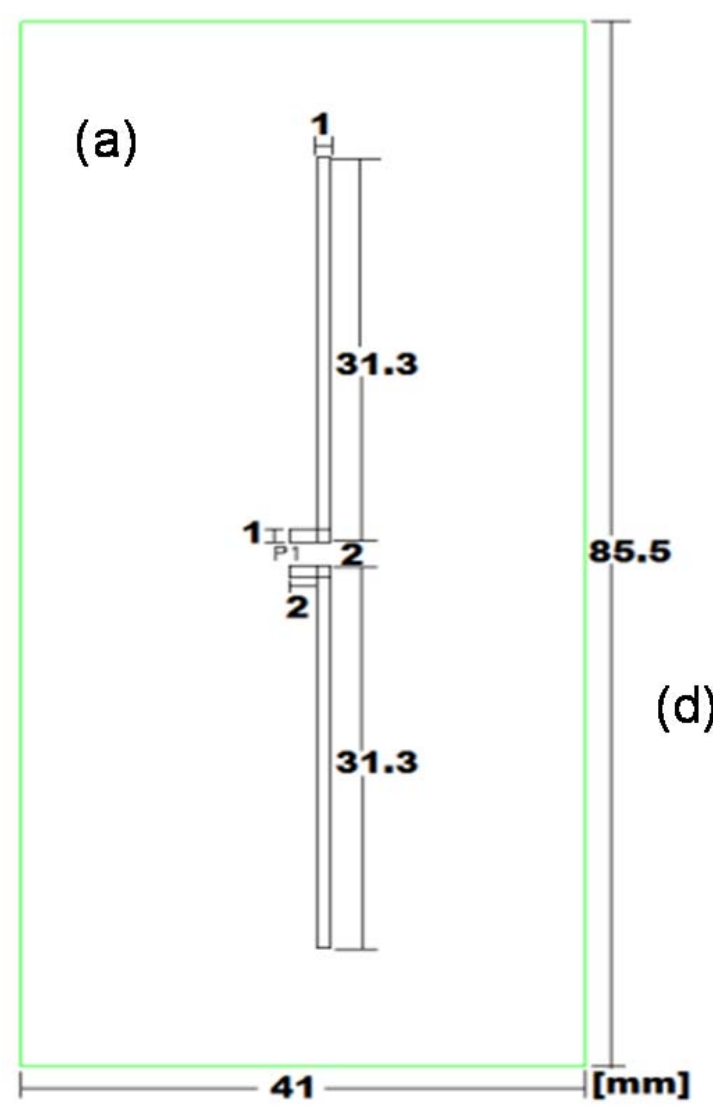

(b)

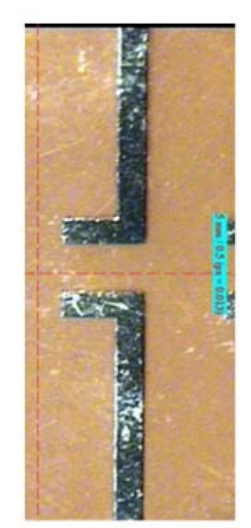

(c)

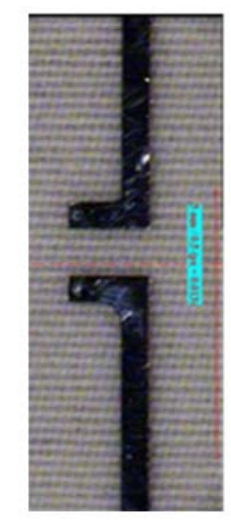

(d)

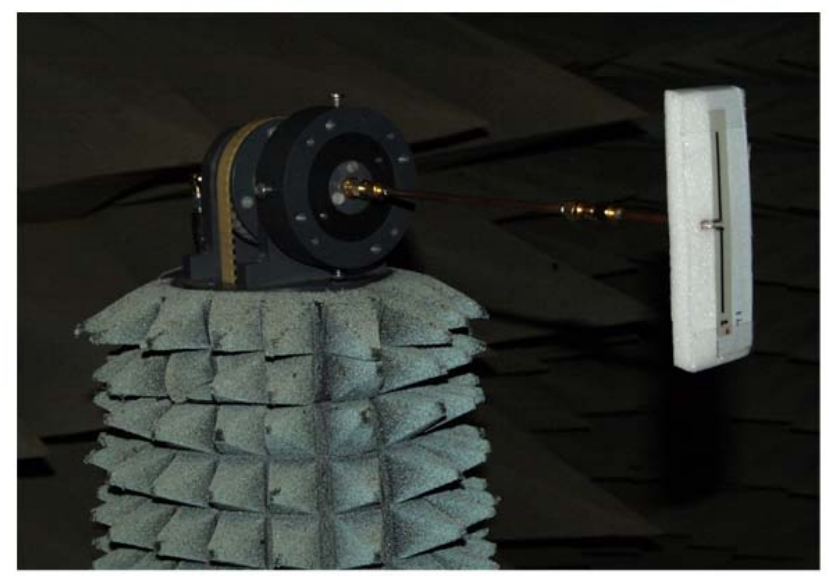

Figure 5. Dipole: (a) Geometry and dimensions; digital microscope image of dipole on (b) Kapton film and (c) ICS 2 L and (d) printed dipole in an anechoic chamber

Table 1, shows the measurements of DC resistance of several inkjet printed dipole arms on Kapton film, Polyurethane coated fabric (PCF) Stretchable fabric and polyester cotton with/without an Interface Coated Substrate (ICS) with varying number of ink layers. The DC resistance was measured using a Solartron Schlumberger Digital Multimeter. Results with multiple samples give an indication as to the repeatability of the fabrication method. These results confirm that it is very difficult to print directly onto fabrics and the resulting DC resistance is very large unless many layers are printed at the expense of time, cost and edge resolution. The ICS layer demonstrates significant improvement in this regard and a $2^{\text {nd }}$ ink jet layer further reduces the resistance. Although the Kapton film in not textile, it has been included as to allow comparison of the surface roughness of the different textiles. A closer inspection using SEM images and digital microscope of the dipole printed tracks on 
Final author version. Paper published in IET Microwaves, Antennas \& Propagation, Volume 7, Issue 9, 18 June 2013, p. 760 - 767, DOI: 10.1049/iet-map.2013.0076, Print ISSN 1751-8725, Online ISSN 1751-8733

stretchable fabric revealed micro cracks along the tracks. These micro cracks are likely to be caused by the elasticity of the fabric. Albeit, the existence of these deformations, we have successfully demonstrated the possibility to realise conducting ink jet printed circuits on such fabrics with reasonable DC resistances. Additional layers of conductive ink tend to distort the edges of the antenna - this was particularly true without the interface layer.

Table 1. DC Resistance (ohms) of 31.3mm long inkjet printed dipole arms.

\begin{tabular}{|c|c|c|c|c|c|c|c|}
\hline $\begin{array}{c}\text { Substrate } \\
\text { material }\end{array}$ & $\begin{array}{c}\text { Inkjet } \\
\text { layers }\end{array}$ & $\begin{array}{c}\text { Dipole } \\
\mathbf{1}\end{array}$ & Dipole 2 & $\begin{array}{c}\text { Dipole } \\
\mathbf{3}\end{array}$ & $\begin{array}{c}\text { Dipole } \\
\mathbf{4}\end{array}$ & $\begin{array}{c}\text { Dipole } \\
\mathbf{5}\end{array}$ & Mean \\
\hline Polyester Cotton & 1 & $864 ;$ & $910 ; 955$ & $1251 ;$ & $970 ;$ & $754 ;$ & 954.4 \\
& & 1012 & & 1124 & 920 & 784 & \\
\hline Polyester Cotton & 2 & $126 ;$ & $108 ; 101$ & $104 ;$ & $152 ;$ & $151 ;$ & 118.2 \\
& & 101 & & 119 & 105 & 115 & \\
\hline Polyester Cotton & 3 & $55 ; 42$ & $43 ; 49$ & $52 ; 50$ & $64 ; 59$ & $57 ; 59$ & 53.0 \\
\hline Polyester Cotton & 5 & $23 ; 14$ & $15 ; 14$ & $19 ; 15$ & $15 ; 15$ & $17 ; 13$ & 16.0 \\
\hline Kapton & 1 & $3.7 ; 3.6$ & $3.9 ; 3.8$ & $3.6 ; 3.3$ & $3.6 ; 3.3$ & $3.5 ; 3.5$ & 3.6 \\
\hline PCF Stretchable & 2 & $13.5 ;$ & $20.1 ;$ & $13.5 ;$ & $12.5 ;$ & $12.1 ;$ & 14.7 \\
Fabric & & 15.4 & 11.2 & 20.9 & 13.3 & 14.8 & \\
\hline $\begin{array}{c}\text { Polyester Cotton } \\
\text { with interface layer }\end{array}$ & 1 & $28.5 ;$ & $27.2 ;$ & $27.6 ;$ & $\begin{array}{c}\text { Only } 3 \\
\text { samples }\end{array}$ & $\begin{array}{c}\text { Only } 3 \\
\text { samples } \\
\text { created }\end{array}$ & 25.2 \\
\hline $\begin{array}{c}\text { Polyester Cotton } \\
\text { with interface layer }\end{array}$ & 2 & $2.7 ; 3.5$ & $2.8 ; 2.8$ & $3.0 ; 4.0$ & $3.5 ; 2.8$ & $\begin{array}{c}\text { Only } 4 \\
\text { samples } \\
\text { created }\end{array}$ & 3.1 \\
\hline
\end{tabular}

\section{Antenna Design and Results}

\subsection{Prototype fabrication}

One of the major challenges in the realisations of fabric antennas prototypes is how a transmission line or cable can be robustly connected to the antenna's input terminals ensuring that a match load of $50 \Omega$ is achieved. In order to validate the performance of the inkjet printed dipoles discussed in this paper, a simple unbalanced feed was adopted. This consisted of a $50 \Omega$ semi rigid cable having the inner and outer parts connected separately to the dipole arms. It is to be noted that for the dipoles on Kapton film, silver epoxy was used to connect the terminals together, whilst for the dipoles on ICS it was possible to use low 
Final author version. Paper published in IET Microwaves, Antennas \& Propagation, Volume 7, Issue 9, 18 June 2013, p. 760 - 767, DOI: 10.1049/iet-map.2013.0076, Print ISSN 1751-8725, Online ISSN 1751-8733

temperature solder. This is advantageous in terms of reliable fabrication and matching as solder typically has a higher conductivity than epoxy.

To ensure repeatable results, the dipole antennas were physically supported by a $10 \mathrm{~mm}$ thick Rohacell slab measuring $85.5 \mathrm{~mm} \times 41 \mathrm{~mm}$. This platform enabled us to carry out measurements in an anechoic chamber; see Figure 5 (d). In this set-up, the antenna under test was placed at distance of $225 \mathrm{~mm}$ away from the positioner in order to minimise any reflections from the positioner.

\subsection{Electromagnetic simulations}

3-D finite-difference time-domain (FDTD) using EMPIRE XCcel ${ }^{\mathrm{TM}}$ commercial software has been used to simulate the $\lambda / 2$ dipoles. The inkjet printed dipole was placed $225 \mathrm{~mm}$ away from the cylindrical positioner post which has a radius of $36 \mathrm{~mm}$, see Figure 5 (d). The post is made of Acrylonitrile Butadiene Syrene (ABS), and has a relative permittivity and loss tangent $(\tan \delta)$ of 2.91 and 0.025 respectively. The permittivity of the substrate and the conductivity of the ink were adjusted to match the resonant frequencies and efficiencies to the measured results.

\subsection{Simulated and measured results}

Simulated and measured return loss results are shown in Figure 6. All the antennas were well matched. The differences in the antenna resonance frequencies were due to the dielectric loading of the ICS and Kapton film. The simulated frequency matched the measured results when $\varepsilon_{r}=3.5$ ('Simulated Sample 1') was used for the ICS substrate and $\varepsilon_{\mathrm{r}}$ $=1.88$ ('Simulated Sample 2') for the Kapton substrate. 


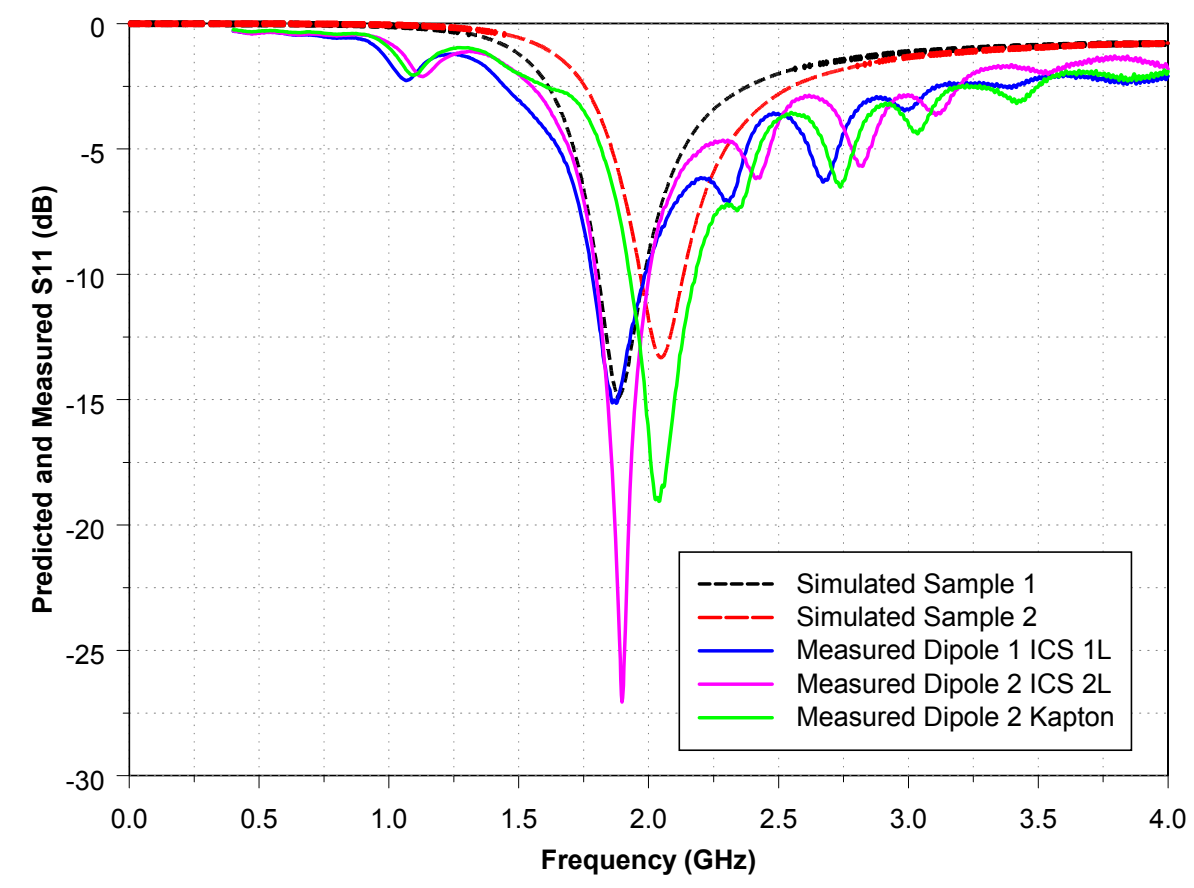

Figure 6. The comparison between simulated and measured return loss.

The performance of the antennas is summarised in

Table 2. The simulated antenna efficiency was $92 \%$ with a highly conducting layer $(\sigma=5.88$ $\left.x 10^{7} \mathrm{~S} / \mathrm{m}\right)$. To replicate the measured efficiency $(\sim 80 \%)$, the conductivity of the simulated uniform metallic tracks was reduced to $5.6 \times 10^{6} \mathrm{~S} / \mathrm{m}$ which gives an indication to the conductivity of the ink tracks. The measured printed track on the interface layer had an efficiency of $60 \%$ which is reasonable for many applications. This was increased to $74 \%$ with two layers of inkjet printing. The efficiency for the dipole on the stretchable fabric was $31.6 \%$ with two layers of printed ink. The cotton/polyester with the interface layer antenna had a higher efficiency than the Plastibert stretchable fabric version - this is assumed to be due to two factors: i) the reduced surface roughness of the interface layer $(5 \mu \mathrm{m}$ compared to 10 $20 \mu \mathrm{m}$ for the Plastibert) which is essential for printing continuous tracks and secondly ii) the inadvertent flexing of the stretchable fabric caused cracks in the printed conducted layer. 
Final author version. Paper published in IET Microwaves, Antennas \& Propagation, Volume 7, Issue 9, 18 June 2013, p. 760 - 767, DOI: 10.1049/iet-map.2013.0076, Print ISSN 1751-8725, Online ISSN 1751-8733

To demonstrate the effect of the interface layer, a dipole was fabricated with 5 layers of inkjet printing directly onto the fabric without the interface layer. Without the interface, the inkjet printed layers spread into the fabric causing ill-defined dipole arms shorting out the gap between the two arms. The problems caused by poorly-defined lines become more severe at higher frequencies. This indicates the practical difficulties of printing directly onto fabric. It is worthy of note that the dipole with only one inkjet layer on the interface layer had a better efficiency than with 5 layers of conducting ink on the polyester cotton. Therefore, the interface layer saves time, reduces costs, improves the printing resolution and enhances the RF performance. Note, that the positioner in the measurement system is also included in the simulations which affected the gain and increased it above the expected value for a dipole of $2.2 \mathrm{dBi}$. Therefore the efficiency is a more reliable measure of the antenna performance. The measured and simulated radiation patterns with the positioner are considered in the next section.

Table 2. Simulated and measured antenna parameters of inkjet printed dipoles at resonance frequency.

\begin{tabular}{|l|c|c|c|c|c|c|}
\hline Substrate & $\begin{array}{c}\text { Inkjet } \\
\text { layers }\end{array}$ & $\begin{array}{c}\text { Freq } \\
(\mathbf{M H z})\end{array}$ & $\begin{array}{c}\mathbf{S}_{\mathbf{1 1}} \\
(\mathbf{d B})\end{array}$ & $\begin{array}{c}\text { Gain } \\
(\mathbf{d B i})\end{array}$ & $\begin{array}{c}\text { 10dB BW } \\
(\mathbf{M H z})\end{array}$ & $\begin{array}{c}\text { Efficiency } \\
(\%)\end{array}$ \\
\hline Simulated sample 1 & - & 1890 & 14.9 & 2.64 & 180 & 78.1 \\
\hline Simulated sample 2 & - & 2005 & 13.3 & 2.94 & 168 & 79.9 \\
\hline $\begin{array}{l}\text { Meas: Polyester cotton } \\
\text { with interface layer }\end{array}$ & 1 & 1875 & 15.2 & 2.24 & 205 & 60.2 \\
\hline $\begin{array}{l}\text { Meas: Polyester cotton } \\
\text { with interface layer }\end{array}$ & 2 & 1897 & 27.1 & 3.60 & 205 & 74.1 \\
\hline Meas: Kapton & 1 & 2040 & 19.1 & 3.16 & 255 & 85.1 \\
\hline $\begin{array}{l}\text { Meas: PCF stretchable } \\
\text { fabric }\end{array}$ & 2 & 2128 & 9.4 & 0.68 & $\begin{array}{c}\text { N/A - Not } \\
\text { matched to } \\
10 \mathrm{~dB}\end{array}$ & 31.6 \\
\hline Meas: Polyester cotton & 5 & 1840 & 21.1 & 1.92 & 283 & 56.6 \\
\hline $\begin{array}{l}\text { Meas: Etched on low } \\
\text { loss laminate }\end{array}$ & - & 1778 & 17.1 & 3.45 & 180 & 77.5 \\
\hline
\end{tabular}




\subsection{Measured radiation patterns}

Figure 7 shows the measured patterns at resonance of the inkjet printed dipoles. These measured radiation patterns show that the printed antennas have dipole-like patterns. The patterns were reasonably isotropic in the azimuth plane - however the effect of the positioner can be seen. However, pattern squinting is noticeable in the elevation plane which is attributed to the arms not being exactly straight and asymmetries in the printed arms.

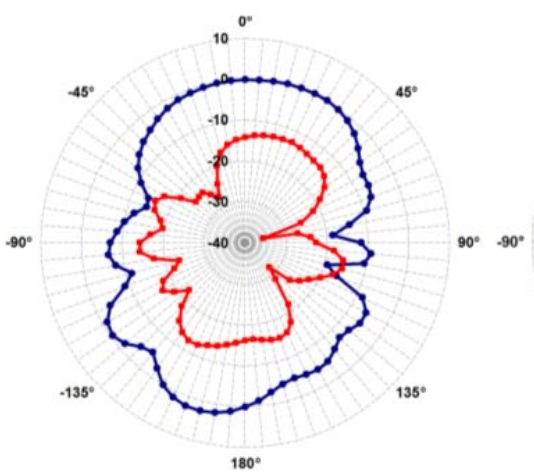

(a) ICS $1 \mathrm{~L}$ at $1875 \mathrm{MHz} ; \Phi=0^{\circ}$

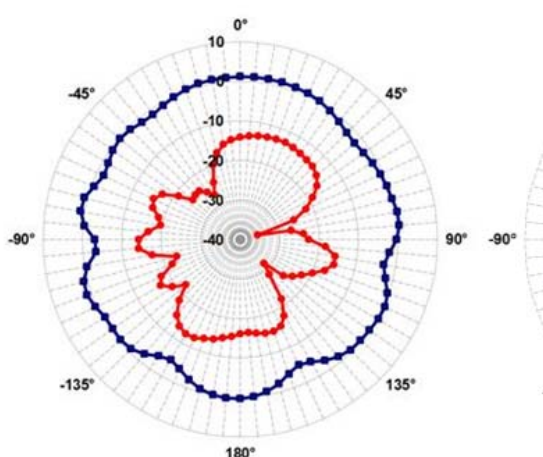

(d) ICS 1L at

$1875 \mathrm{MHz} ; \Phi=90^{\circ}$

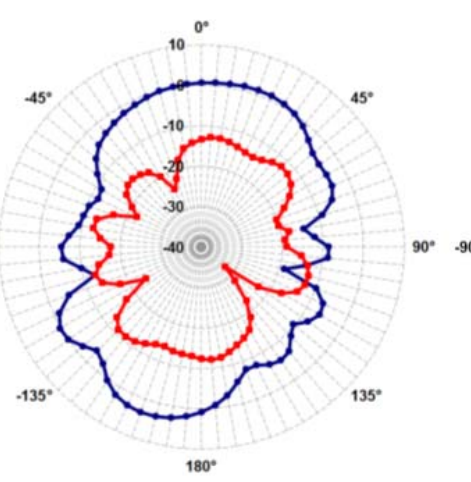

(b) ICS $2 \mathrm{~L}$ at $1897.5 \mathrm{MHz} ; \Phi=0^{\circ}$

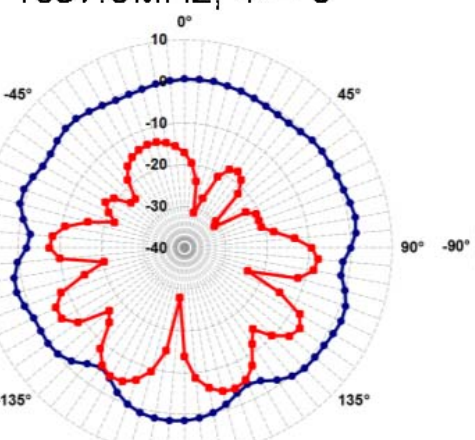

(e) ICS $2 L^{180^{\circ}}$ at $1897.5 \mathrm{MHz} ; \Phi=90^{\circ}$

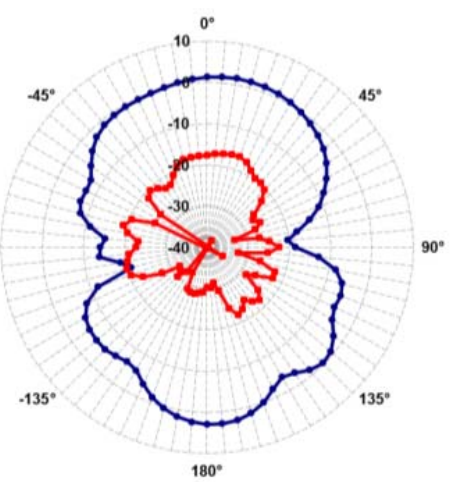

(c) Kapton at $2040 \mathrm{MHz} ; \Phi=0^{\circ}$

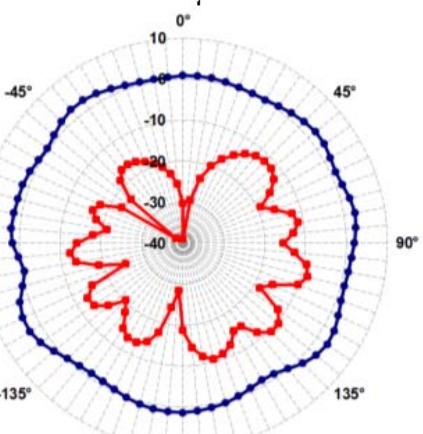

$180^{\circ}$

(f) Kapton at $2040 \mathrm{MHz} ; \Phi=90^{\circ}$

Figure 7. Measured radiation patterns of inkjet printed dipoles at resonance frequency: (a) ICS $1 \mathrm{~L}$ at $1875 \mathrm{MHz}, \Phi=0^{\circ}$; (b) ICS $2 \mathrm{~L}$ at $1897.5 \mathrm{MHz} \Phi=0^{\circ}$; (c) Kapton at $2040 \mathrm{MHz} \Phi=0^{\circ}$; (d) ICS $1 \mathrm{~L}$ at $1875 \mathrm{MHz}, \Phi=90^{\circ}$; (e) ICS $2 \mathrm{~L}$ at $1897.5 \mathrm{MHz} \Phi=90^{\circ}$; (f) Kapton at $2040 \mathrm{MHz} \Phi=90^{\circ}$. Note $E_{\Phi}$ is blue and $E_{\theta}$ is red 
Final author version. Paper published in IET Microwaves, Antennas \& Propagation, Volume 7, Issue 9, 18 June 2013, p. 760 - 767, DOI: 10.1049/iet-map.2013.0076, Print ISSN 1751-8725, Online ISSN 1751-8733

The positioner in the anechoic chamber (see Figure 5 (d)) was included in the simulations (see Figure 8 inset). Note the vertical tower was covered with radar absorbing material and therefore was not included in the simulations. Figure 8 shows the 2-D simulated antenna pattern with the positioner results at $1890 \mathrm{MHz}$. The positioner affects the radiation patterns, particularly noticeable at about $225^{\circ}$ and $315^{\circ}$ in the 2-D polar plot. This shows that for antennas without a ground plane, it is important to consider the effect of the positioner. The radiation plots at $1.89 \mathrm{GHz}$ show that the positioner can enhance the directivity of the dipolethis explains the gain values above $2.2 \mathrm{dBi}$ in Table 2 . Simulations verified that the effect of the positioner was minimised by increasing the separation of the dipole from the positioner in the measurements.

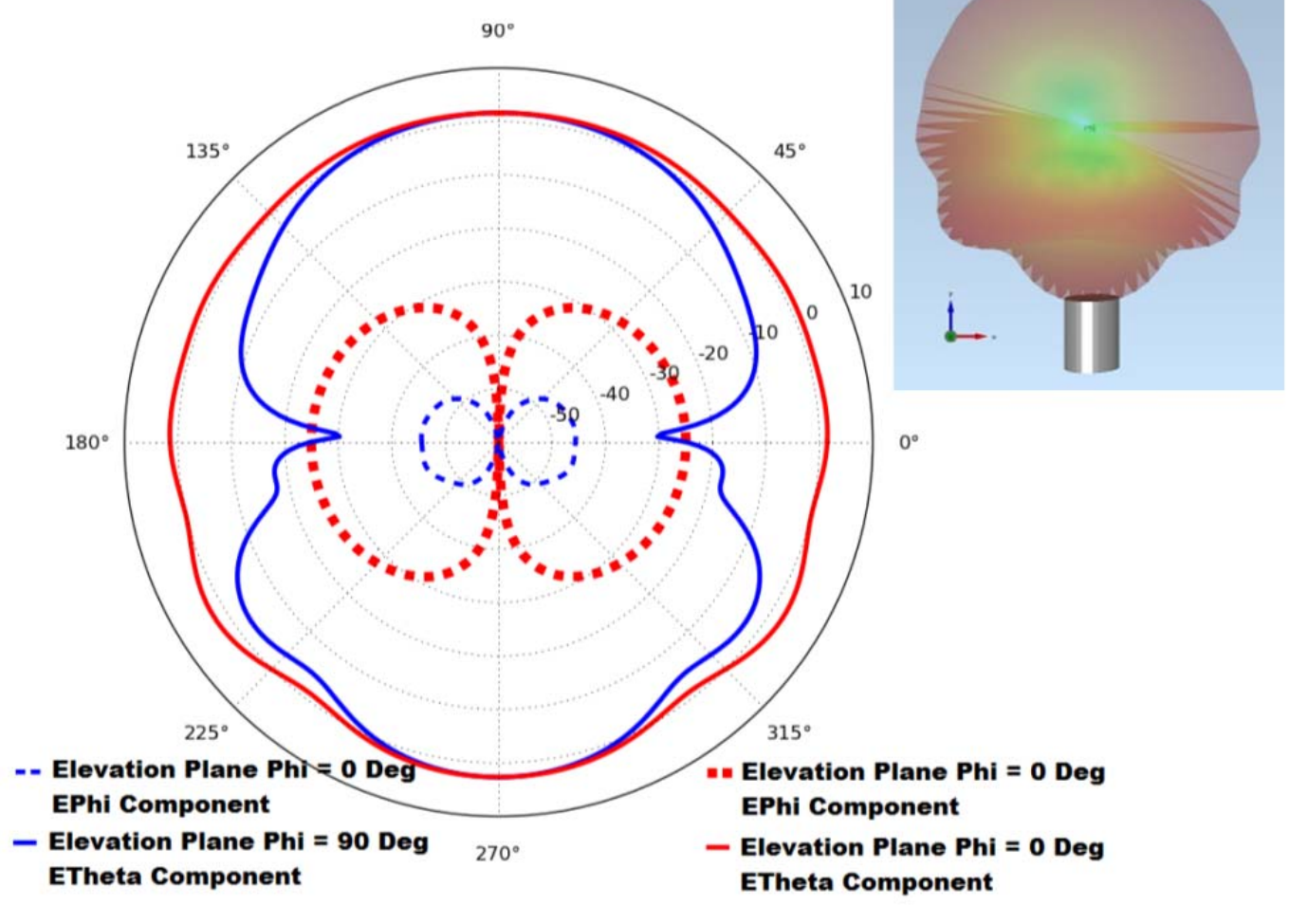

Figure 8. Simulated radiation patterns at $1.89 \mathrm{GHz}$ with the positioner and 3D view (inset). 
Final author version. Paper published in IET Microwaves, Antennas \& Propagation, Volume 7, Issue 9, 18 June 2013, p. 760 - 767, DOI: 10.1049/iet-map.2013.0076, Print ISSN 1751-8725, Online ISSN 1751-8733

\section{Conclusions}

This paper has demonstrated a new manufacturing technique for wearable antennas by using inkjet printing in conjunction with an interface layer. The surface of textiles is inherently rough and is therefore not naturally suitable for thin film inkjet printing - this has been confirmed with DC measurements. This has been overcome by first screen printing an interface layer which converts the fabric into a smooth surface. DC measurements of the resistance have been compared with efficiency results of printed antennas and have been shown to be a reasonable estimate of the RF antenna performance. This can be useful for fast quality control in the manufacturing process. Efficiencies of more than $70 \%$ have been achieved. The efficiency was increased by using two layers of printing. The antenna efficiency with one inkjet printed layer on the interface layer was greater than using 5 inkjet layers without the interface layer. Therefore, the interface layer saves time, cost and results in improved edge definition. The radiation patterns were not exactly symmetric - this was thought to be due to asymmetries in the printing process and the arms not being perfectly aligned. However, as the application is for wearable antennas - this is acceptable as the human body will inherently affect the patterns.

\section{References}

[1] X. Tao, Smart fibres, fabrics and clothing. Cambridge, UK: Woodhead Publishing Limited, 2001.

[2] B. Sanz-Izquierdo, J. C. Batchelor, and M. I. Sobhy, "Button antenna on textiles for wireless local area network on body applications," Microwaves, Antennas \& Propagation, IET, vol. 4, no. 11, pp. 1980-1987, 2010.

[3] C. Hertleer, H. Rogier, S. Member, L. Vallozzi, and L. Van Langenhove, "A Textile Antenna for Off-Body Communication Integrated Into Protective Clothing for Firefighters," Simulation, vol. 57, no. 4, pp. 919-925, 2009.

[4] T. Kellomäki, W. G. Whittow, J. Heikkinen, and L. Kettunen, "2.45 GHz plaster antennas for health monitoring," in European Conference on Antennas \& Propagation (EUCAP), 2009. 
Final author version. Paper published in IET Microwaves, Antennas \& Propagation, Volume 7, Issue 9, 18 June 2013, p. 760 - 767, DOI: 10.1049/iet-map.2013.0076, Print ISSN 1751-8725, Online ISSN 1751-8733

[5] B. Gupta, S. Sankaralingam, and S. Dhar, "Development of wearable and implantable antennas in the last decade: A review," in Microwave Symposium (MMS), 2010 Mediterranean, 2010, pp. 251-267.

[6] N. H. M. Rais, P. J. Soh, F. Malek, S. Ahmad, N. B. M. Hashim, and P. S. Hall, "A Review of Wearable Antenna," in Loughborough Antennas \& Propagation Conference (LAPC), 2009, no. November, pp. 225-228.

[7] T. F. Kennedy, P. W. Fink, A. W. Chu, N. J. Champagne, G. Y. Lin, and M. A. Khayat, "Body-Worn E-Textile Antennas: The Good , the Low-Mass, and the Conformal," IEEE Trans. Antennas and Propagation, vol. 57, no. 4, pp. 910-918, 2009.

[8] P. S. Hall and Y. Hao, Antennas and Propagation for Body-Centric Wireless Communications. London, UK: Artech House, 2012.

[9] S. L. Cotton and W. G. Scanlon, "Channel Characterization for Single- and MultipleAntenna Wearable Systems Used for Indoor Body-to-Body Communications," IEEE Transactions on Antennas and Propagation, vol. 57, no. 4, pp. 980-990, Apr. 2009.

[10] D. Sanchez-Hernandez, High frequency electromagnetic dosimetry. Artech House Inc., 2009.

[11] Q. Bai and R. Langley, "Crumpling of PIFA Textile Antenna," IEEE Trans. Antennas and Propagation, vol. 60, no. 1, pp. 63-70, 2012.

[12] P. Salonen and Y. Rahmat-Samii, "Textile Antennas: Effects of Antenna Bending on Input Matching and Impedance Bandwidth," IEEE Aerospace and Electronic Systems Magazine, vol. 22, no. 12, pp. 18-22, 2007.

[13] P. Vincenzini and C. Carfagna, "Washable screen printed textile antennas," Advances in Science and Technology, vol. 80, pp. 118-122, 2012.

[14] J. Lilja, P. Salonen, T. Kaija, and P. de Maagt, "Design and Manufacturing of Robust Textile Antennas for Harsh Environments," IEEE Transactions on Antennas and Propagation, vol. 60, no. 9, pp. 4130-4140, Sep. 2012.

[15] C. Hertleer, a. Van Laere, H. Rogier, and L. Van Langenhove, "Influence of Relative Humidity on Textile Antenna Performance," Textile Research Journal, vol. 80, no. 2, pp. 177-183, Sep. 2009.

[16] J. C. G. Matthews and G. Pettitt, "Development of Flexible , Wearable Antennas," in European Conference on Antennas \& Propagation (EuCAP), 2009, pp. 273-277.

[17] P. J. Massey, "Mobile phone fabric antennas integrated within clothing," in 11th IEE International Conference on Antenna and Propagation, 2001, no. 480, pp. 344-347.

[18] M. Klemm, I. Locher, and G. Troster, "A Novel Circularly Polarized Textile Antenna for Wearable Applications," in 7th European Conference on Wireless Technology, 2004, pp. $285-288$.

[19] P. Salonen, Y. Rahmat-Samii, H. Hurme, and M. Kivikoski, "Dual-band wearable textile antenna," in IEEE Antennas and propagation society international symposium, 2004, pp. 463-466. 
Final author version. Paper published in IET Microwaves, Antennas \& Propagation, Volume 7, Issue 9, 18 June 2013, p. 760 - 767, DOI: 10.1049/iet-map.2013.0076, Print ISSN 1751-8725, Online ISSN 1751-8733

[20] P. Salonen and A. Hurme, "A novel fabric WLAN antenna for wearable applications," in IEEE Antenna and propagation society international symposium, 2003, pp. 700703.

[21] M. Tanaka and J. H. Jang, "Wearable microstrip antenna," in IEEE Antenna and Propagation Society International Symposium, 2003, pp. 704-707.

[22] A. Chauraya, S. Zhang, W. G. Whittow, T. Acti, R. Seager, T. Dias, and Y. Vardaxoglou, "Addressing the Challenges of Fabricating Microwave Antennas Using Conductive Threads," in The 6th European Conference on Antennas \& Propagation (EUCAP), 2012.

[23] T. Kellomaki, J. Virkki, S. Merilampi, and L. Ukkonen, "Towards washable wearable antennas: a comparison of coating materials for screen-printed textile-based UHF RFID tags," International Journal of Antennas and Propagation, vol. 2012, pp. 1-11, 2012.

[24] L. Yang, S. Member, R. Zhang, and D. Staiculescu, "A Novel Conformal RFIDEnabled Module Utilizing Inkjet-Printed Antennas and Carbon Nanotubes for GasDetection Applications," IEEE Antennas and Wireless Propagation Letters, vol. 8, pp. 653-656, 2009.

[25] S. L. Merilampi, T. Bjorninen, A. Vuorimaki, L. Ukkonen, P. Ruuskanen, and L. Sydanheimo, "The effect of conductive ink layer thickness on the functioning of printed UHF RFID antennas," Proceedings of the IEEE, vol. 98, no. 9, pp. 1610-1619, 2010.

[26] I. Locher and G. Troster, "Screen-printed Textile Transmission Lines," Textile Research Journal, vol. 77, no. 11, pp. 837-842, Nov. 2007.

[27] S. Merilampi, T. Björninen, V. Haukka, P. Ruuskanen, L. Ukkonen, and L. Sydänheimo, "Analysis of electrically conductive silver ink on stretchable substrates under tensile load," Microelectronics Reliability, vol. 50, pp. 2001-2011, 2010.

[28] A. Rida, L. Yang, R. Vyas, S. Bhattacharya, and M. M. Tentzeris, "Design and Integration of Inkjet-printed Paper-Based UHF Components for RFID and Ubiquitous Sensing Applications," in European Microwave Conference, 2007, no. October, pp. 724-727.

[29] A. Rida, L. Yang, R. Vyas, and M. M. Tentzeris, "Conductive Inkjet-Printed Antennas on Flexible Low-Cost Paper-Based Substrates for RFID and WSN Applications," IEEE Antennas and Propagation Magazine, vol. 51, no. 3, pp. 13-23, 2009.

[30] A. Rida, G. Shaker, F. Nasri, T. Reynolds, and S. Nikolaou, "Inkjet Printing of Dual Band Conformal Antenna for Use in Wifi Frequency Bands," in IEEE Radio and Wireless Symposium (RWS), 2010, pp. 65-67.

[31] B. V. Lakafosis, A. Rida, R. Vyas, L. Yang, S. Nikolaou, and M. M. Tentzeris, "Progress Towards the First Wireless Sensor Networks Consisting of Inkjet-Printed, Sensor Tags," Proceedings of the IEEE, vol. 98, no. 9, pp. 1601-1609, 2010. 
Final author version. Paper published in IET Microwaves, Antennas \& Propagation, Volume 7, Issue 9, 18 June 2013, p. 760 - 767, DOI: 10.1049/iet-map.2013.0076, Print ISSN 1751-8725, Online ISSN 1751-8733

[32] B. Shao, Q. Chen, Y. Amin, J. Hllstedt, R. Liu, H. Tenhunen, and L. Zheng, "Processdependence of inkjet printed folded dipole antenna for $2.45 \mathrm{GHz}$," in European Conference on Antennas \& Propagation (EuCAP), 2009, pp. 2336-2339.

[33] M. Mäntysalo and P. Mansikkamäki, "An inkjet-deposited antenna for $2.4 \mathrm{GHz}$ applications," AEU - International Journal of Electronics and Communications, vol. 63, no. 1, pp. 31-35, Jan. 2009.

[34] V. K. Palukuru, K. Sanoda, V. Pynttäri, T. Hu, R. Mäkinen, M. Mäntysalo, J. Hagberg, and $\mathrm{H}$. Jantunen, "Inkjet-Printed RF Structures on BST-Polymer Composites: An Application of a Monopole Antenna for 2.4 GHz Wireless Local Area Network Operation," International Journal of Applied Ceramic Technology, vol. 8, no. 4, pp. 940-946, Jul. 2011.

[35] K. Kirschenmann, K. W. Whites, and S. M. Woessner, "Inkjet Printed Microwave Frequency Multilayer Antennas," in IEEE Antennas and Propagation Society International Symposium, 2007, no. 1, pp. 924-927.

[36] J. Virtanen, T. Björninen, L. Ukkonen, K. Kaija, T. Joutsenoja, L. Sydänheimo, and A. Z. Elsherbeni, "The Effect of Conductor Thickness in Passive Inkjet Printed RFID Tags," in IEEE Antennas and Propagation Society International Symposium (APSURSI), 2010, no. 1, pp. 1-4.

[37] A. Kanso, E. Arnaud, T. Monédière, and M. Thévenot, "Inkjet Printing of Coplanar Wire-Patch Antenna on a Flexible Substrate," in International Symposium of Antenna Technology and Applied Electromagnetics (ANTEM), 2012.

[38] A. Babar, J. Virtanen, V. a. Bhagavati, L. Ukkonen, a. Z. Elsherbeni, P. Kallio, and L. Sydanheimo, "Inkjet-printable UHF RFID tag antenna on a flexible ceramic- polymer composite substrate," 2012 IEEE/MTT-S International Microwave Symposium Digest, Jun. 2012.

[39] F. Yi, L. Luhai, X. Zhiqing, Z. Wen, P. Material, and B. Area, "Research on conductive performance of inkjet printing samples by conductive inkjet ink," in IEEE International Symposium on Microwave, Antenna, Propagation and EMC Technologies for Wireless Communications, 2009, pp. 63-66.

[40] Y. Li, R. Torah, S. Beeby, and J. Tudor, "Inkjet printed flexible antenna on textile for wearable applications Inkjet printed flexible antenna on textile for wearable applications," in Textile Institute World Conference, 2012.

[41] W. G. Whittow, "Capacitive coupling of discrete micro-sized gaps for RF applications," IET Microwaves, Antennas \& Propagation, vol. 6, no. 13, pp. 1481-1486, 2012.

[42] Y. Li, R. Torah, S. P. Beeby, and J. M. Tudor, "An all-inkjet printed flexible capacitor for wearable applications," in Symposium on Design, Test, Integration and Packaging of MEMS/MOEMS (DTIP), 2012.

[43] A. Pique and D. B. Chrisey, Direct-write technologies for rapid prototyping applications, sensors, electronics, and integrated power sources. Academic Press, 2002. 